\title{
POLYMORPHISM OF THE PLASMODIUM FALCIPARUM MULTIDRUG RESISTANCE AND CHLOROQUINE RESISTANCE TRANSPORTER GENES AND IN VITRO SUSCEPTIBILITY TO AMINOQUINOLINES IN ISOLATES FROM THE PERUVIAN AMAZON
}

\author{
MARIA CECILIA HUAMAN, NORMA RONCAL, SHUSUKE NAKAZAWA, TON THAT AI LONG, LUCIA GERENA, \\ CORALITH GARCIA, LELY SOLARI, ALAN J. MAGILL, AND HIROJI KANBARA \\ Institute of Tropical Medicine, Nagasaki University, Nagasaki, Japan; Instituto de Medicina Tropical Alexander von Humboldt, \\ Universidad Peruana Cayetano Heredia, Lima, Peru; Department of Parasitology, Naval Medical Research Center Detachment, Lima, \\ Peru; Walter Reed Army Institute of Research, Silver Spring, Maryland
}

\begin{abstract}
In vitro drug sensitivity to chloroquine (CQ), mefloquine (MQ) and quinine was investigated in 60 cultureadapted Plasmodium falciparum isolates from malaria patients in Padrecocha, a village in the Amazonian Department of Loreto, Peru. All isolates showed resistance to CQ, decreased susceptibility to quinine, and sensitivity to MQ. These isolates were examined for mutations in the $P$. falciparum multidrug resistance 1 ( $p f m d r l)$ and chloroquine resistance transporter ( $p f c r t)$ genes previously linked to CQ resistance. The mutations N86Y and D1246Y, two of the five mutations commonly observed in the pfmdr1 gene of CQ-resistant clones, were not found. The pfcrt mutation K76T, associated with CQ resistance, was identified in all the isolates tested. Sequence analysis of codons 72-76 in the pfcrt gene showed the haplotypes SVMNT and CVMNT.
\end{abstract}

\section{INTRODUCTION}

Malaria is increasingly a serious burden in most tropical countries and a major cause of death in children in subSaharan Africa. The situation became more difficult since resistant Plasmodium falciparum strains appeared in late 1950s. ${ }^{1-3}$ In South America, the first $P$. falciparum strains resistant to chloroquine (CQ) were reported in 1961 in Colombia ${ }^{4}$ and Brazil. ${ }^{5}$

Peru, the country with the second highest number of malaria cases in South America, ${ }^{6,7}$ used CQ extensively until 1998. In 1999, the National Malaria Control Program of the National Institutes of Health of $\mathrm{Peru}^{8}$ reported 30-70\% therapeutic failures to CQ. Subsequently, the combination of sulfadoxine/pyrimethamine $(\mathrm{S} / \mathrm{P})$ was introduced for the treatment of uncomplicated $P$. falciparum malaria. Singledose primaquine was also given concurrently as a gametocytocidal agent.

Since CQ resistance was first described, great efforts have been made to understand the mechanism and, two relevant proteins, Pgh $1^{9}$ and PfCRT, ${ }^{10}$ have been identified as candidates that participate in CQ resistance. The $P$. falciparum multidrug resistance gene 1 (pfmdrl) analog codes for Pgh1 and the $P$. falciparum chloroquine resistance transporter gene ( $p f c r t)$ codes for PfCRT. These genes are located on chromosomes 5 and 7, respectively. Both proteins are localized in the food vacuole membrane and may modulate CQ uptake and/ or $\mathrm{pH}$ regulation. ${ }^{11}$

It has been proposed that point mutations in the $p f m d r 1$ gene producing amino acid changes at positions $86,184,1034$, 1042, and 1246 are associated with CQ and quinine resistance, as well as increased levels of susceptibility to mefloquine (MQ). ${ }^{9,12}$ In other studies, pfcrt mutations at codons 74, 75, $76,220,271,326,356$, and 371 , have been related to CQ resistance. ${ }^{11}$ Notably, mutation $\mathrm{K} 76 \mathrm{~T}$ is consistently found in CQ-resistant strains ${ }^{11,13}$ and its contribution to CQ resistance has been recently elucidated by transfection experiments. ${ }^{14}$ Results from experiments conducted with laboratory strains need to be corroborated by those obtained from field isolate studies. Based on field studies, geographic variation in the parasite line due to regional differences has been observed. ${ }^{11,15}$

There is little information in Peru about molecular characterization of $P$. falciparum strains. To determine the prevalence of CQ resistance-associated markers, haplotype analysis of the pfcrt and $p f m d r l$ genes was performed in Peruvian $P$. falciparum isolates from the Amazonian Department of Loreto.

\section{MATERIALS AND METHODS}

Study site. Padrecocha is a village of 1,400 inhabitants on the Nanay River, $5 \mathrm{~km}$ northwest of Iquitos, the departmental capital of Loreto, Peru. An epidemiologic study ${ }^{16}$ was carried out in Padrecocha from August 1997 to July 1998, and of 4,046 blood smears obtained, $36 \%$ were positive for malaria parasites. Plasmodium falciparum was found in $17 \%$ of all positive cases and $P$. vivax was found in $83 \%$. Due to widespread and frequent therapeutic failures of CQ for $P$. falciparum malaria in this area, the currently recommended treatment is $\mathrm{S} / \mathrm{P}, 25 \mathrm{mg}$ and $1.25 \mathrm{mg} / \mathrm{kg}$, respectively, and primaquine, $0.75 \mathrm{mg} / \mathrm{kg}$ administrated as a single dose. Therapeutic failures with $\mathrm{S} / \mathrm{P}$ are treated with quinine and tetracycline in adults or quinine and clindamycin in children. Plasmodium vivax malaria is treated with a standard regimen of CQ for three days.

Isolates of $\boldsymbol{P}$. falciparum. Plasmodium falciparum isolates were collected from 64 patients with uncomplicated acute $P$. falciparum malaria in Padrecocha from March to May 1999. Patients enrolled in the therapeutic efficacy trial were asked to donate $5 \mathrm{~mL}$ of venous blood. The trial was conducted with a modified version of the Pan American Health Organization template protocol for conducting therapeutic efficacy trials in the Americas. ${ }^{17}$ Individual, written, informed consent was obtained from all participants. The trial was conducted under the Walter Reed Army Institute of Research protocol No. 719 approved by the U. S. Army Surgeon General Human Subjects Research Review Board and the Universidad Peruana Cayetano Heredia Institutional Review Board. Each sample was collected into two microtubes and cryopreserved in liquid 
nitrogen as previously described ${ }^{18}$ in Iquitos, and later transported to the Naval Medical Research Center Detachment Laboratory in Lima. One microtube of each sample was used for the drug resistance test after being successfully culture adapted. The second tube was used for DNA extraction and gene analysis.

Laboratory strains. The CQ-sensitive $P$. falciparum strain FCR3 from The Gambia and the CQ-resistant strain K1 from Thailand were used as controls for the detection of $p f m d r 1$ polymorphism and direct sequencing analysis of pfcrt gene. These strains were propagated in vitro in the Department of Protozoology, Institute of Tropical Medicine, Nagasaki University (Nagasaki, Japan).

Drug sensitivity testing. In vitro susceptibilities to antimalarials were examined by the inhibition test of ${ }^{3} \mathrm{H}$-labeled hypoxanthine uptake in cultures of field-collected parasites, as previously described. ${ }^{19}$ Briefly, a microtube sample was thawed for culture adaptation of 2-6 weeks. Sixty of the 64 collected samples successfully adapted to culture were tested for susceptibility to CQ diphosphate, MQ hydrochloride, and quinine citrate. Drugs were dispensed in $25-\mu \mathrm{L}$ aliquots of two-fold serial dilutions into 96-well, flat bottom microplates to achieve the following final concentrations: $\mathrm{CQ}=\mathrm{CQ}$ : $1,000 \mathrm{ng} / \mathrm{mL}(0.98 \mathrm{ng} / \mathrm{mL})$, quinine $=1,000 \mathrm{ng} / \mathrm{mL}(0.98 \mathrm{ng} /$ $\mathrm{mL})$, and $\mathrm{MQ}=250 \mathrm{ng} / \mathrm{mL}(0.24 \mathrm{ng} / \mathrm{mL})$.

Two strains of $P$. falciparum were used as controls for the in vitro assays: strain D6, which is MQ resistant but otherwise drug sensitive and strain $\mathrm{W} 2$, which is $\mathrm{CQ}$ and quinine resistant, but MQ sensitive. ${ }^{20,21}$ Both strains were obtained from Dr. Dennis Kyle (Walter Reed Army Institute of Research, Washington DC).

The results of these assays are reported as the $50 \%$ inhibitory concentration $\left(\mathrm{IC}_{50}\right)$ of the respective drug, that is, the concentration of drug, usually in $\mathrm{ng} / \mathrm{mL}$, added to the culture that inhibits $50 \%$ of growth of the parasites.

In vitro $\mathrm{CQ}$ resistance can be defined as the ability of $P$. falciparum isolates to grow at a CQ concentration of $100 \mathrm{nM}$ or $33 \mathrm{ng} / \mathrm{mL}$ in culture. ${ }^{3,21}$ The cut-off value nicely separates CQ sensitivity, which is well below $33 \mathrm{ng} / \mathrm{mL}$, and CQ resistance, which is above the cut-off value. Clear, reproducible, and unambiguous results can be obtained with carefully controlled assay conditions that avoid $\mathrm{pH}$ variations, variable serum activity, inaccurate gas conditions, inoculum effects, and other variations such as poorly growing parasites.

Extraction of DNA. Two hundred microliters each from 60 samples was subjected to DNA extraction using QIAamp DNA Blood kit (Qiagen, Valencia, CA) to yield $200 \mu \mathrm{L}$ of genomic DNA. The DNA was then eluted and stored in elution buffer, according to the manufacturer's instructions and used for a polymerase chain reaction (PCR) immediately or stored at $-20^{\circ} \mathrm{C}$.

Detection of $\boldsymbol{p f m \boldsymbol { d r }} \mathbf{1}$ gene polymorphism. To determine the presence of sequence polymorphisms in pfmdr1, a PCRrestriction fragment length polymorphism method was used. For this purpose, a nested PCR procedure (nest 1, nest 2) was carried out. The region encompassing the polymorphic codons 86 and 184 was amplified using primers dr2 (5'AGATGGTAACCTCAGTAT-3') and dr3 (5'-AGTCTTTTCTCCACAATA-3') and region encompassing the polymorphic codons 1034, 1042, and 1246 was obtained using primers dr5 (5'-GAAATGTTTAAAGATCCAAG-3') and dr6 (5'-CAGCAAACTTACTAACAC-3') in nest 1 . The de- sign of primers was based on the complete nucleotide sequence of the previously published GH2 strain (National Center for Biotechnology Information Gene Bank, accession number S53996). Figure 1 shows the amplification strategy based on a previously reported protocol. ${ }^{22}$ Nest 1 amplification conditions were one cycle at $94^{\circ} \mathrm{C}$ for two minutes, an amplification of 35 cycles $\left(94^{\circ} \mathrm{C}\right.$ for 30 seconds, $45^{\circ} \mathrm{C}$ for one minute, and $72^{\circ} \mathrm{C}$ for one minute), and a final extension at $72^{\circ} \mathrm{C}$ for five minutes. Two microliters of PCR products obtained in nest 1 were used for the second amplification, nest 2, by using primers A4, A2, 1034f, 1042r, 1246f, and dr6. The amplification conditions for nest 2 were as previously reported and the products were subjected to enzyme digestion. $^{22}$ This technique produces digestion patterns corresponding to alternative polymorphisms following resolution by electrophoresis on 1-3\% agarose gels (Nusieve 3:1; BioWhittaker Molecular Applications, Rockland, ME). The reaction conditions for enzyme digestion were as previously described. $^{22}$ The PCR reagents were obtained from the TaKaRa Shuzo Co. (Kyoto, Japan). Restriction enzyme digestions were done with Apo I (New England Biolabs, Inc., Beverly, MA) Dra I (Takara Shuzo Co.), Dde I (SigmaAldrich, Inc., St. Louis, MO), Vsp I (Gibco-BRL, Gaithersburg, MD), and Eco RV (Takara Shuzo Co.) for the characterization of codons $86,184,1034,1042$, and 1246, respectively.

Amplification of the pfcrt gene. To amplify the pfcrt gene, a PCR was carried out using primers cr5 (5'-TATAGATTATTTTCATTGTCTTCCACAT-3') and cr6 (5'-TTCCTTATAAAGTGT AATGCGATAG-3') in nest 1 . For the second amplification, nest 2, the previously reported primers 23402 up and $24011 \mathrm{dn}^{15}$ were used to amplify the region encompassing the polymorphic codons 72-76 and 97 in exon 2 . Nest 1 amplification conditions were one cycle at $94^{\circ} \mathrm{C}$ for two minutes, an amplification of 35 cycles $\left(94^{\circ} \mathrm{C}\right.$ for 30 seconds, $50^{\circ} \mathrm{C}$ for one minute, and $60^{\circ} \mathrm{C}$ for two minutes), and a final extension at $60^{\circ} \mathrm{C}$ for 10 minutes. Nest 2 amplification was carried out according to previously reported conditions. ${ }^{15}$

Direct DNA sequence analysis. The PCR amplification products were purified using a QIAquick PCR purification kit (Qiagen) and sequenced directly on an ABI310 automated sequencer using the ABI PRISM Big Dye Terminator Cycle kit (Applied Biosystems, Foster City, CA) following the manufacturer's instructions.

Data and statistical analysis. Data for the in vitro drug sensitivity test were analyzed by non-linear regression. The $\mathrm{IC}_{50}$

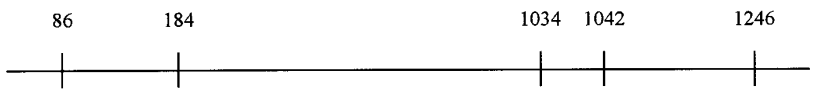

$\mathrm{dr} 2$

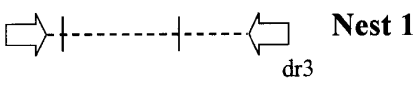

A2

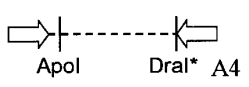

dr5

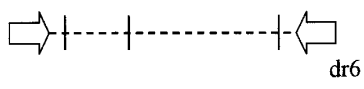

$1034 \mathrm{f} \quad 1246 \mathrm{f}$

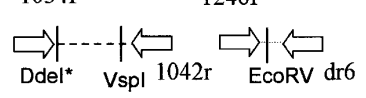

FIGURE 1. Schematic representation of the nested system used for the detection of polymorphisms in the Plasmodium falciparum multidrug resistance 1 gene. The asterisks show artificially constructed restriction endonuclease sites. 
of tested isolates was compared with that of the D6 and W2 strains, and the mean $\mathrm{IC}_{50} \mathrm{~s}$ were compared using the Student's $t$-test. SPSS software for Windows (SPSS Inc., Chicago, IL) was used.

\section{RESULTS}

Susceptibility of $P$. falciparum isolates to $C Q, M Q$, and quinine. The in vitro susceptibility data for $C Q, M Q$, and quinine for 60 Peruvian isolates, and the profile of control strains D6 and W2 are shown in Table 1. The $\mathrm{IC}_{50} \mathrm{~s}$ to CQ of the isolates ranged from 29 to $35 \mathrm{ng} / \mathrm{mL}$ and were much higher than the one showed by the CQ-sensitive control strain, which ranged from 1 to $5 \mathrm{ng} / \mathrm{mL}$. The Peruvian isolates were at the lower level of $\mathrm{IC}_{50}$ values usually seen in CQ-resistant isolates. All isolates showed high $\mathrm{IC}_{50}$ values for quinine, ranging from 45 to $56 \mathrm{ng} / \mathrm{mL}$, consistent with decreased susceptibility. They also showed low $\mathrm{IC}_{50}$ values for $\mathrm{MQ}$, which ranged from 2.06 to $2.41 \mathrm{ng} / \mathrm{mL}$, consistent with sensitivity to this drug.

Polymorphism of the $\boldsymbol{p} \boldsymbol{f m d r 1}$ and $\boldsymbol{p} \boldsymbol{f} \boldsymbol{c r t}$ genes. Analysis of the pfmdr1 gene showed wild type codons at positions 86 (Asn) and 1246 (Asp). However, at codons 184, 1034, and 1042, the substitutions Y184F, S1034C, and N1042D were found in all samples. The $p f m d r 1$ polymorphisms at codons 86 and 184 of representative Peruvian $P$. falciparum isolates are shown in Figure 2. The $p f m d r 1$ haplotype for all 60 Peruvian isolates was NFCDD for positions 86, 184, 1034, 1042, and 1246, respectively.

Analysis of the pfcrt gene showed that the K76T substitution was present in all Peruvian $P$. falciparum isolates evaluated. The DNA sequences at polymorphic codons 72, 74, 75, and 97 were also analyzed. At position 72, cysteine and serine (encoded by TCT, $\mathrm{S}_{\mathrm{tct}}$ ) were found. The deduced haplotypes of the pfcrt gene at positions 72-76 and 97 are shown in Table 2.

Genotyping of $\boldsymbol{P}$. falciparum. Codons $72-76$ of the Peruvian isolates were sequenced and the haplotypes SVMNT (30 of $60,50 \%$ ) and CVMNT were found. CVMNT and SVMNT are haplotypes previously reported for laboratory strains

TABLE 1

In vitro susceptibilities of the Peruvian isolates and control strains of Plasmodium falciparum to chloroquine (CQ), mefloquine (MQ), and quinine*

\begin{tabular}{|c|c|c|c|}
\hline & \multicolumn{3}{|c|}{$\mathrm{IC}_{50}(\mathrm{ng} / \mathrm{mL})$} \\
\hline & Chloroquine & Mefloquine & Quinine \\
\hline \multicolumn{4}{|c|}{ Peruvian isolates $(\mathrm{n}=60)$} \\
\hline Geometric mean & 29.24 & 2.13 & 45.74 \\
\hline Mean & 31.83 & 2.23 & 50.1 \\
\hline $95 \% \mathrm{CI}$ & $28.36-35.30$ & $2.06-2.41$ & $44.53-55$. \\
\hline \multicolumn{4}{|l|}{ Control strains } \\
\hline \multicolumn{4}{|c|}{ D6 (MQ-R, otherwise S) } \\
\hline Mean & 3.72 & 6.65 & 13.17 \\
\hline SD & 0.29 & 1.63 & 0.64 \\
\hline Profile & $1-5(\mathrm{~S})$ & 8-15 (R) & $8-15(\mathrm{~S})$ \\
\hline \multicolumn{4}{|c|}{$\begin{array}{l}\mathrm{W} 2 \text { (CQ-R and } \\
\text { quinine-R, MQ-S) }\end{array}$} \\
\hline Mean & 43.19 & 3.14 & 75.43 \\
\hline SD & 4.09 & 0.45 & 4.26 \\
\hline Profile & $35-100(\mathrm{R})$ & $0.5-3(\mathrm{~S})$ & $35-100(\mathrm{R})$ \\
\hline
\end{tabular}

inhibitory concentration; $\mathrm{CI}=$ confidence interval; $\mathrm{R}=$ resistant; $\mathrm{S}=$ sensitive.

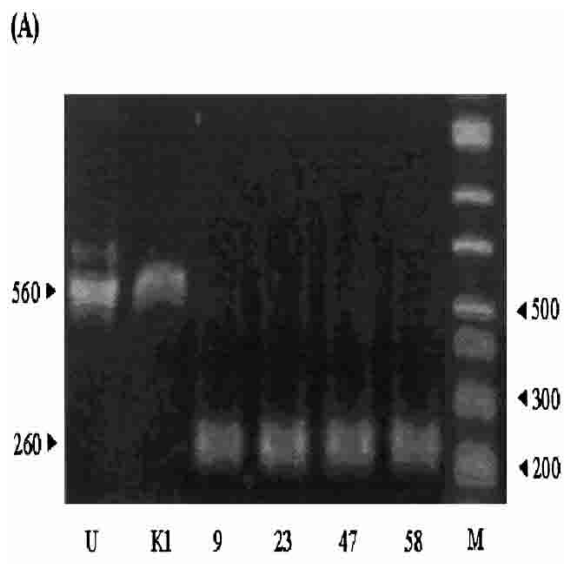

(B)

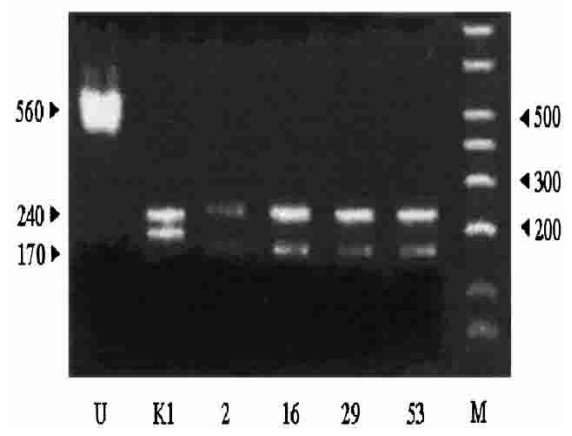

Figure 2. Agarose gel electrophoresis of restriction enzyme-digested products used in the polymorphism analysis of the Plasmodium falciparum multidrug resistance 1 gene in Peruvian isolates. A, Apo I digest for codon 86. Peruvian isolates show wild-type Asn. B, Dra I digest for codon 184. Peruvian isolates show the Y184F mutation. $\mathrm{U}=$ undigested product; $\mathrm{K} 1=P$. falciparum $\mathrm{K} 1$ strain; $\mathrm{M}=$ molecular size markers. Values along the gels are in basepairs.

from Ecuador and Brazil, respectively, ${ }^{11}$ and in field samples from Peru. ${ }^{23}$ These two haplotypes showed the same in vitro susceptibility pattern to CQ $(P=0.21)$, MQ $(P=0.69)$, and quinine $(P=0.11)$. Figure 3 shows scatter plots of the data. No polyclonal infections were found in any of the tested alleles.

\section{DISCUSSION}

In this study, we report the prevalence of known genetic polymorphisms of the pfmdr1 and pfcrt genes and the in vitro

TABLE 2

Plasmodium falciparum chloroquine resistance transporter gene mutations in isolates from Peru*

\begin{tabular}{llllll}
\hline & \multicolumn{5}{c}{ Amino acid position } \\
\cline { 2 - 6 } & 72 & 74 & 75 & 76 & 97 \\
\hline CQ-sensitive strains & $\mathrm{C}$ & $\mathrm{M}$ & $\mathrm{N}$ & $\mathrm{K}$ & $\mathrm{H}$ \\
$\quad$ All regions & & & & & \\
CQ-resistant strains & $\mathrm{C}$ & $\mathrm{I}$ & $\mathrm{E}$ & $\mathrm{T}$ & $\mathrm{H}$ \\
$\quad$ Southeast Asia and Africa & $\mathrm{S}$ & $\mathrm{M}$ & $\mathrm{N}$ & $\mathrm{T}$ & - \\
$\quad$ Papua New Guinea & $\mathrm{S} / \mathrm{C}$ & $\mathrm{M}$ & $\mathrm{N}$ & $\mathrm{T}$ & $\mathrm{H}$ \\
$\quad$ Peruvian isolates & & & & & \\
\hline
\end{tabular}




\section{CHLOROQUINE}
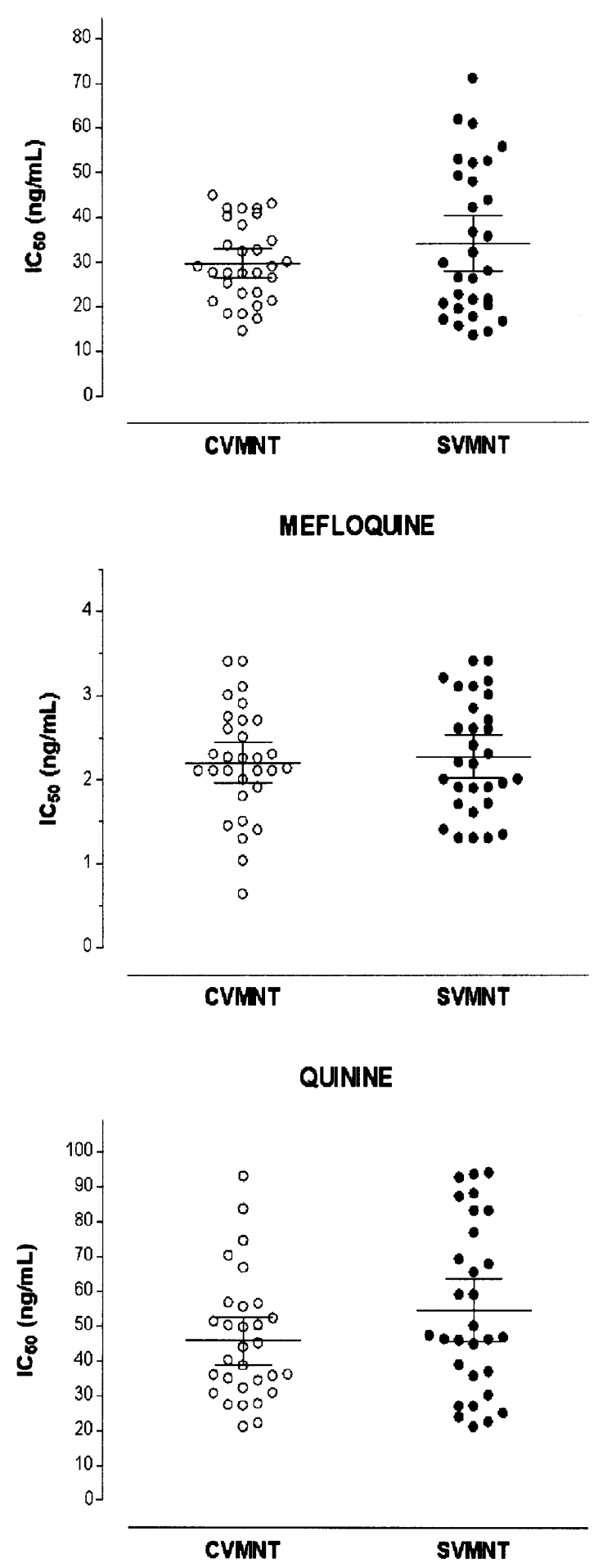

\section{2-76 position pfcrt haplotype}

FIGURE 3. In vitro susceptibilities to chloroquine, mefloquine, and quinine in Peruvian isolates of Plasmodium falciparum with the deduced CVMNT and SVMNT haplotypes in the $P$. falciparum chloroquine resistance transporter ( $p f c r t$ ) gene. $50 \%$ inhibitory concentrations $\left(\mathrm{IC}_{50} \mathrm{~s}\right)$ were compared using the Student's $t$-test. Bars show the mean and $95 \%$ confidence intervals. drug susceptibility profiles against the aminoquinoline-based antimalarial drugs in $P$. falciparum isolates from the Peruvian Amazon.

A total of 60 culture-adapted isolates were subjected to the drug sensitivity test for CQ, quinine, and MQ. All isolates were moderately $\mathrm{CQ}$ resistant. This result was not unexpected since CQ resistance have been observed in Peru since $1992,{ }^{24}$ and more than $30 \%$ of the reported cases of malaria in 1998 showed therapeutic failure to CQ treatment. ${ }^{25}$ The fact that all isolates showed a narrow range of $\mathrm{IC}_{50} \mathrm{~s}$ against the three aminoquinoline-based drugs tested might reflect the presence of a uniform $P$. falciparum population in Padrecocha village. Therefore, imported clones rather than indigenous parasites, which had acquired drug resistance, might have spread in the area. Conversely, we should consider that these isolates do not entirely represent the $P$. falciparum population because they were once selected by a culture condition.

The mutation Y184F was identified in the $p f m d r 1$ gene of all CQ-resistant Peruvian strains analyzed in this study. It had been previously reported for CQ-resistant laboratory strains ${ }^{9}$ and field isolates. ${ }^{26}$ However, the mutation N86Y was not found in the same CQ-resistant strains, in contrast to studies carried out in Malaysia, ${ }^{27}$ Indonesia, ${ }^{28}$ Guinea-Bissau, ${ }^{29} \mathrm{Ni}$ geria, ${ }^{30}$ and sub-Saharan Africa,${ }^{31}$ but in agreement with a study carried out in Brazil. ${ }^{26}$ Other clinical studies in Uganda, ${ }^{32}$ Laos, $^{33}$ Cameroon, ${ }^{34}$ and southern Africa ${ }^{35}$ reported that the N86Y mutation in $p f m d r 1$ was not predictive of treatment outcome. In addition to the mutations Y184F and N86Y, other three-point mutations in pfmdr1 gene, previously related to $\mathrm{CQ}$ resistance, quinine resistance, and $\mathrm{MQ}$ sensitivity, were studied. The point mutations S1034C and N1042D were identified in our isolates, but D1246Y was not detected. Reed and others ${ }^{12}$ investigated the role of Cys 1034, Asp 1042, and Tyr 1246 in aminoquinoline-based drug resistance by using transfection technology. They reported that the three mutations play a role in resistance to quinine, as well as in the sensitivity to MQ, and suggested that Tyr 1246 is a pivotal player in MQ sensitivity. This suggestion is contradictory to the results with our MQ-sensitive isolates, in which such a mutation was absent.

Previous studies evaluated $p f m d r 1$ and $p f c r t$ genes, and suggested that mutations in $p f m d r 1$ may confer some advantage to the parasite in the presence of $\mathrm{CQ}$, increasing the level of CQ resistance. ${ }^{36,37}$ When mutations are present in both genes, $\mathrm{IC}_{50} \mathrm{~s}$ to $\mathrm{CQ}$ are higher than when only mutations in the $p f c r t$ gene are found. In our study, two of five mutations studied in $p f m d r 1$ were not present in the Peruvian isolates. This may explain the low levels of CQ resistance observed in our isolates. The detection of only one pattern of pfmdr1 mutations in this area again supports the idea that imported clones with the same drug-resistant characteristics might spread.

With regard to the $p f c r t$ gene, all Peruvian isolates showed the CQ-resistant phenotype and the K76T mutation. Our results are in agreement with those reported by Fidock and others, ${ }^{11}$ Djimde and others, ${ }^{36}$ and Vieira and others ${ }^{38}$ on in vitro susceptibility profiles. In addition, previous reports suggested that this mutation is the major determinant for $\mathrm{CQ}$ resistance, but the clinical outcome might involve other factors. ${ }^{32-34,37}$

Sequencing of the pfcrt gene identified two haplotypes, 
CVMNT and SVMNT, at codons 72-76. The SVMNT haplotype was previously found in laboratory strains of $P$. falciparum from Brazil, ${ }^{15}$ and the CVMNT haplotype was related to Ecuadorian and Colombian strains. ${ }^{15}$ Recently, Cortese and others ${ }^{23}$ studied drug resistance mutations in South American isolates, including 16 Peruvian samples, and identified these two haplotypes.

Aramburu and others ${ }^{6}$ speculated that three types of drugresistant $P$. falciparum isolates converged in the Iquitos region of Peru. These are S/P-resistant CQ-resistant parasites from Brazil, variably $\mathrm{S} / \mathrm{P}$-resistant CQ-resistant parasites from the Loreto region, and $\mathrm{S} / \mathrm{P}$-sensitive $\mathrm{CQ}$-sensitive parasites from coastal Peru. With regard to this hypothesis, our study suggests that the $P$. falciparum population in Padrecocha village in Iquitos includes Brazilian strains with the SVMNT haplotype, which correlates well with CQ and S/P resistance (Huaman MC and others, unpublished data), and Loretana strains with the CVMNT haplotype, which correlates with $\mathrm{CQ}$ resistance and $\mathrm{S} / \mathrm{P}$ variable resistance. This finding suggests that SVMNT and CVMNT haplotypes might be useful markers of strain origin that would be complementary to merozoite surface protein-1 (MSP-1), MSP-2, glutamate-rich protein, and microsatellite markers.

In conclusion, we suggest that the two types of $P$. falciparum strains with low-grade resistance to aminoquinolines were recently introduced into Iquitos in the Peruvian Amazon and spread without further mutations.

Received February 3, 2003. Accepted for publication August 29, 2003.

Acknowledgments: We are grateful to Thomas E. Wellems for valuable comments on the manuscript, and to Dennis Kyle for providing the control strains D6 and W2. We also thank Maria del Carmen Parquet for her assistance with the molecular techniques, and Windell Rivera and Humberto Guerra for their kind help during this work.

Financial support: this study was partially supported by the Pan American Health Organization. Maria Cecilia Huaman and Ton That Ai Long are recipients of the "Monbusho Scholarship" awarded by the Ministry of Education, Science, Sports and Culture of the Government of Japan.

Disclaimer: The views expressed by the authors in this report do not necessarily reflect the views of the U. S. Army, U. S. Navy, or the Department of Defense.

Authors' addresses: Maria Cecilia Huaman, Shusuke Nakazawa, and Ton That Ai Long, Institute of Tropical Medicine, Nagasaki University, Sakamoto 1-12-4, Nagasaki 852-8523, Japan. 1-12-4 Sakamoto, Nagasaki 852-8523, Japan, Telephone: 81-95-849-7838, Fax: 81-95849-7805. Norma Roncal, Instituto de Medicina Tropical Alexander von Humboldt, Universidad Peruana Cayetano Heredia, AP 4314, Lima 100, Peru, Telephone: 51-1-482-3903, Fax: 51-1-482-3404. Lucia Gerena, Walter Reed Army Institute of Research, Washington, DC 20307-5100, Fax: 301-319-9449. Coralith Garcia and Lely Solari, Universidad Peruana Cayetano Heredia, Av. Honorio Delgado 430, San Martin de Porras, Lima. Peru, Telephone: Phone 51-1-319000. Alan J. Magill, Walter Reed Army Institute of Research, Silver Spring MD 20910-7500, Telephone: 301-319-9959, Fax: 301-319-9585. Hiroji Kanbara: Institute of Tropical Medicine, Nagasaki University, Sakamoto 1-12-4, Nagasaki 852-8523, Japan, Telephone: 81-95-849-7838, Fax: 81-95-849-7805. E-mail: f0512@cc.nagasaki-u.ac.jp.

\section{REFERENCES}

1. Payne D, 1987. Spread of chloroquine resistance in Plasmodium falciparum. Parasitol Today 3: 241-246.

2. Wongsrichanalai C. Pickard AL, Wernsdorfer WH, Meshnick
SR. 2002. Epidemiology of drug-resistant malaria. Lancet Infect Dis 2: 209-218.

3. Wellems TE. Plowe CV. 2001. Chloroquine-resistant malaria. $J$ Infect Dis 184: 770-776.

4. Moore DV, Lanier JE, 1961. Observations on two Plasmodium falciparum infectious with abnormal response to chloroquine. Am J Trop Med Hyg 10: 5-6.

5. Rodriguez DP, 1961. Casos de malaria por Plasmodium falciparum resistentes ao tratamento pela chloroquina. Arch Higiene Saude Publica 26: 231-235.

6. Aramburu J, Ramal C, Witzig R, 1999. Malaria reemergence in the Peruvian Amazon region. Emerg Infect Dis 5: 209-215.

7. WHO, 1999. World Health Report 1999. http://www.who.int/whr/ 1999/en/report.htm.

8. Instituto Nacional de Salud, 2000. National Policy of Antimalarials in Peru. Report of the National Program for Malaria Control. Lima, Peru: MINSA.

9. Foote SJ, Kyle DE, Martin RK, Oduola AM, Forsyth K, Kemp DJ, Cowman AF, 1990. Several alleles of the multidrugresistance gene are closely linked to chloroquine resistance in Plasmodium falciparum. Nature 345: 255-258.

10. Wellems TE, Walker-Jonah A, Panton LJ, 1991. Genetic mapping of the chloroquine-resistance locus on Plasmodium falciparum chromosome 7. Proc Natl Acad Sci USA 88: 3382-3386.

11. Fidock DA, Nomura T, Talley AK, Cooper RA, Dzekunov SM, Ferdig MT, Ursos LMB, Singh Sidhu AB, Naude B, Deitsch KW, Su XZ, Wootton JC, Roepe PD, Wellems TE, 2000. Mutations $\mathrm{n}$ the $P$. falciparum digestive vacuole transmembrane protein PfCRT and evidence for their role in chloroquine resistance. Mol Cell 6: 861-871.

12. Reed MB, Saliba KJ, Caruana SR, Kirk K, Cowman AF, 2000 Pgh1 modulates sensitivity and resistance to multiple antimalarials in Plasmodium falciparum. Nature 403: 906-909.

13. Chen N, Russell B, Staley J, Kotecka B, Nasveld P, Cheng Q, 2001. Sequence polymorphisms in $p f c r t$ are strongly associated with chloroquine resistance in Plasmodium falciparum. J Infect Dis 183: 1543-1545.

14. Singh Sidhu AB, Verdier-Pinard D, Fidock DA, 2002. Chloroquine Resistance in Plasmodium falciparum malaria parasites conferred by pfcrt mutations. Science 298: 210-213.

15. Mehlotra RK, Fujioka H, Roepe PD, Janeeh O, Ursos LMB, Jacobs-Lorena V, McNamara DT, Bockarie MJ, Kazura JW, Kyle DE, Fidock DA, Zimmerman PA, 2001. Evolution of a unique Plasmodium falciparum chloroquine-resistance phenotype in association with pfcrt polymorphism in Papua New Guinea and South America. Proc Natl Acad Sci 98: 1268912694.

16. Roper MH, Carrion RS, Cava CG, Andersen EM, Aramburu JS, Calampa C, Hightower AW, Magill AJ, 2000. The epidemiology of malaria in an epidemic area of the Peruvian amazon. Am J Trop Med Hyg 62: 247-256.

17. Pan American Health Organization, 1998. Evaluation of the Therapeutic Efficacy of Drugs for Treatment of Uncomplicated Plasmodium falciparum Malaria in the Americas. OPS/HCP/ HCT/113/98 Washington, DC: Pan American Health Organization.

18. Pavanand K, Permpanich B, Chuanak N, Sookto P, 1974. Preservation of Plasmodium falciparum-infected erythrocytes for in vitro culture. J Parasitol 60: 537-539.

19. Webster HK, Boudreau EF, Pavanand K, Yongvanitchit K, Pang LW, 1985. Antimalarial drug susceptibility testing of Plasmodium falciparum in Thailand using a microdilution radioisotope method. Am J Trop Med Hyg 34: 228-235.

20. Milhous WK, Gerena L, Kyle DE, Oduola AM, 1989. In vitro strategies for circumventing antimalarial drug resistance. Prog Clin Biol Res 313: 61-72.

21. Rathod PK, McErlean T, Lee PC, 1997. Variations in frequencies of drug resistance in Plasmodium falciparum. Proc Natl Acad Sci USA 94: 9389-9393.

22. Duraisingh MT, Jones P, Sambou I, von Seidlein L, Pinder M, Warhurst DC, 2000. The tyrosine-86 allele of the $p f m d r 1$ gene of Plasmodium falciparum is associated with increased sensitivity to the anti-malarials mefloquine and artemisinin. Mol Biochem Parasitol 108: 13-23.

23. Cortese JF, Caraballo A, Contreras CE, Plowe CV, 2002. Origin 
and Dissemination of Plasmodium falciparum drug-resistance mutations in South America. J Infect Dis 189: 999-1006.

24. Castro Rivera, 1993. Estudio epidemiologico del brote de malaria por Plasmodium falciparum en el Valle Bigote, Piura en setiembre de 1992. Tesis para optar el Grado de Medico - Cirujano. Peru. Lima, Peru: Universidad Nacional de Piura.

25. Instituto Nacional de Salud, 1999. Resistencia del Plasmodium falciparum a Medicamentos Antimalaricos en el Peru. Lima, Peru: Informe Tecnico.

26. Zalis MG, Pang L, Silveira MS, Milhous Wilbur K, Wirth D, 1998. Characterization of Plasmodium falciparum isolated from the Amazon region of Brazil: evidence for quinine resistance. $A m$ J Trop Med Hyg 58: 630-637.

27. Cox-Singh J, Singh B, Alias A, Abdullah MS, 1995. Assessment of the association between three point mutations in chloroquine-resistance in vitro of Malaysian Plasmodium falciparum isolates. Trans R Soc Trop Med Hyg 89: 436-437.

28. Gomez-Saladin E, Fryauff DJ, Taylor WRJ, Laksana BS, Susanti AI, Purnomo, Subianto B, Richie TL. 1999. Plasmodium falciparum mdr1 mutations and in vivo chloroquine resistance in Indonesia. Am J Trop Med Hyg 61: 240-244.

29. Adagu IS, Dias F, Pinheiro L, Rombo L, do Rosario V, Warhurst DC, 1996. Guinea Bissau: association of chloroquine resistance of Plasmodium falciparum with Tyr86 allele of multiple drugresistance gene pfmdr1. Trans R Soc Trop Med Hyg 90: 90-91.

30. Adagu IS, Warhurst DC, Carucci DJ, Duraisingh MT, 1995. Pfmdr1 mutations and chloroquine-resistance in Plasmodium falciparum isolates from Zaria, Nigeria. Trans $R$ Soc Trop Med Hyg 89: 132.

31. Basco LK, Le Bras J, Rhoades Z, Wilson CM, 1995. Analysis of pfmdr1 and drug susceptibility in fresh isolates of Plasmodium falciparum from Sub Saharan Africa. Mol Biochem Parasitol 74: $157-166$.
32. Dorsey G, Kamya MR, Singh A, Rosenthal PJ, 2001. Polymorphisms in the Plasmodium falciparum pfcrt and pfmdr-1 genes and clinical response to chloroquine in Kampala, Uganda. $J$ Infect Dis 183: 1417-1420.

33. Pillai DR, Labbe AC, Vanisaveth V, Hongvangthong B, Pomphida S, Inkathone S, Zhong K, Kain KC, 2001. Plasmodium falciparum malaria in Laos: Chloroquine treatment outcome and predictive value of molecular markers. $J$ Infect Dis 183: 789-795.

34. Basco LK, Ringwald P, 2001. Analysis of the key pfcrt point mutation and in vitro and in vivo response to chloroquine in Yaounde, Cameroon. J Infect Dis 183: 1828-1831.

35. McCutcheon KR, Freese JA, Frean JA, Sharp BL, Markus MB, 1999. Two point mutations in the multidrug-resistance gene homologue of Plasmodium falciparum, pfmdr1, are not useful predictors of in-vivo or in-vitro chloroquine resistance in southern Africa. Trans R Soc Trop Med Hyg 93: 300-302.

36. Djimde A, Doumbo OK, Cortese JF, Kayentao K, Doumbo S, Diourte Y, Dicko A, Su XZ, Nomura T, Fidock DA, Wellems TE, Plowe CV. 2001. A molecular marker for chloroquineresistant falciparum malaria. $N$ Engl J Med 344: 257-263.

37. Babiker HA, Pringle SJ, Abdel-Muhsin A, Mackinnon M, Hunt P, Walliker D, 2001. High-level chloroquine resistance in Sudanese isolates of Plasmodium falciparum is associated with mutations in the chloroquine resistance transporter gene $p f c r t$ and the multidrug resistance gene pfmdr1. J Infect Dis 183: $1535-1538$.

38. Vieira P, Alecrim MdG, da Silva LHP, Gonzales-Jimenez I, Zalis MG. 2001. Analysis of the PfCRT K76T Mutation in Plasmodium falciparum Isolates from the Amazon Region of Brazil. $J$ Infect Dis 183: 1832-1833. 